\title{
Implementing Measurement-Based Care for Depression: Practical Solutions for Psychiatrists and Primary Care Physicians
}

This article was published in the following Dove Press journal:

Neuropsychiatric Disease and Treatment

\author{
Ran Ha Hong' \\ Jill K Murphy' \\ Erin E Michalak' \\ Trisha Chakrabarty' \\ Zuowei Wang iD ${ }^{2}$ \\ Sagar V Parikh ${ }^{3}$ \\ Larry Culpepper ${ }^{4}$ \\ Lakshmi N Yatham ' \\ Raymond W Lam (D) ${ }^{1, *}$ \\ Jun Chen (D) ${ }^{5, *}$ \\ 'Department of Psychiatry, University of \\ British Columbia, Vancouver, Canada; \\ ${ }^{2}$ Hongkou Mental Health Center, \\ Shanghai, People's Republic of China; \\ ${ }^{3}$ Department of Psychiatry, University of \\ Michigan, Ann Arbor, MI, USA; \\ ${ }^{4}$ Department of Family Medicine, Boston \\ University, Boston, MA, USA; ${ }^{5}$ Shanghai \\ Mental Health Center, Shanghai, People's \\ Republic of China
}

*These authors contributed equally to this work
Correspondence: Raymond W Lam Department of Psychiatry, University of British Columbia, 2255 Wesbrook Mall, Vancouver, BC V6T 2AI, Canada

$\mathrm{Tel}+$ I 604-822-7325

Email r.lam@ubc.ca

\begin{abstract}
Measurement-based care (MBC) can be defined as the clinical practice in which care providers collect patient data through validated outcome scales and use the results to guide their decision-making processes. Despite growing evidence supporting the effectiveness of $\mathrm{MBC}$ for depression and other mental health conditions, many physicians and mental health clinicians have yet to adopt MBC practice. In part, this is due to individual and organizational barriers to implementing $\mathrm{MBC}$ in busy clinical settings. In this paper, we briefly review the evidence for the efficacy of MBC focusing on pharmacological management of depression and provide example clinical scenarios to illustrate its potential clinical utility in psychiatric settings. We discuss the barriers and challenges for MBC adoption and then address these by suggesting simple solutions to implement MBC for depression care, including recommended outcome scales, monitoring tools, and technology solutions such as cloud-based MBC services and mobile health apps for mood tracking. The availability of $\mathrm{MBC}$ tools, ranging from paper-pencil questionnaires to mobile health technology, can allow psychiatrists and clinicians in all types of practice settings to easily incorporate MBC into their practices and improve outcomes for their patients with depression.
\end{abstract}

Keywords: measurement-based care, major depressive disorder, depression, scales, outcomes, patient-reported outcome measures, implementation, measurement

\section{Introduction}

Depression, or major depressive disorder (MDD), is a common mental health condition that affects people of all ages and is a leading cause of disease burden globally. ${ }^{1,2}$ Although there are many effective, evidence-based treatments for depression, as noted by clinical practice guidelines, ${ }^{3-6}$ remission rates are low with usual treatment indicating that these treatments produce suboptimal responses in clinical practice. ${ }^{7}$ Hence, there remains an unmet need to improve the usual care for depression treatment.

Standardizing the clinical management of patients with MDD is the first step to optimizing outcomes. The principles of clinical management include conducting a biopsychosocial assessment, formulating a differential diagnosis, supporting the patient through education, providing evidence-based treatments, and measuring clinical outcomes. ${ }^{8}$ Measuring clinical outcomes and using the results to guide treatment decisions is termed "measurement-based care" (MBC). ${ }^{9}$ However, unlike other areas of medicine where taking measurements is the norm (eg, blood pressure in patients with hypertension; fasting blood glucose and hemoglobin $\mathrm{A} 1 \mathrm{C}$ in 
patients with diabetes), measuring outcomes is not routine in psychiatry. For mental health, outcome measurement can be accomplished using validated rating scales administered by clinicians or self-completed by patients. Routinely evaluating patients by using validated scales for symptoms, functioning and quality of life can help clinicians modify the course of treatment in a timely manner to better meet the needs of the patient. ${ }^{9}$ Hence, MBC can be applied to patients with any mental health diagnosis and treatment. The use of $\mathrm{MBC}$ has been shown to improve outcomes and quality of care in both psychiatric and primary care practice. ${ }^{10,11}$

Despite the proven benefits of MBC, less than $20 \%$ of psychiatrists employ $\mathrm{MBC}$ in their practice, emphasizing the need to explore reasons for non-participation and to provide effective guidance for $\mathrm{MBC}$ implementation. ${ }^{12}$ With recent technological innovations in the field of medicine, new tools such as measurement feedback system technology and mobile apps for smartphones have been developed to improve the efficacy, applicability and implementation processes associated with $\mathrm{MBC}$, as well as patient satisfaction. ${ }^{13}$ These tools can further empower patients by providing them with the ability to track their progress and become an active participant in their health care. Comprehensive reviews of MBC implementation are available, ${ }^{14}$ but in this paper, we briefly review the benefits and challenges of implementing $\mathrm{MBC}$ with a focus on pharmacological management of depression. We also provide some practical solutions and new technology tools for psychiatrists and primary care clinicians to incorporate $\mathrm{MBC}$ for depression into their clinical practice.

\section{Validated Outcome Scales}

The foundation for MBC is the use of validated outcome scales. Many scales have been developed to measure and understand the impact of chosen therapeutic intervention on the patient's mental health. ${ }^{15}$ Rating scales for MBC have multiple uses, including screening, aiding in diagnosis, informing treatment adjustments and monitoring for relapse. ${ }^{16}$ Validated scales are available to assess clinically relevant outcomes such as symptoms, side effects, functioning, and quality of life. Symptom remission is an important outcome, but the goals of depression treatment should also encompass functional recovery and quality of life, which are higher priorities for patients. ${ }^{8,17}$ Although symptom and functional improvement are often associated, there is clear evidence that they are not highly correlated, nor do they improve along the same time course. ${ }^{18,19}$ Hence, it is important to assess each outcome independently using appropriate scales to ensure that treatment is optimized and that patients achieve symptom remission, functional recovery, and improved quality of life.

For outcome scales to be considered for MBC, they need to be psychometrically valid, reliable, sensitive to change, and relevant to specific setting and purpose. ${ }^{16}$ Care must be taken when evaluating the scales and scores by taking into consideration the context and individual differences of the patients, including their language, culture and cognitive state. ${ }^{16}$ Table 1 lists some examples of validated outcome scales for MBC of depression. The validated scales can be broadly classified into clinicianrated and patient-reported outcome measures (PROMs). Clinician-rated scales are thought to be more comprehensive but take additional training and are more timeconsuming to administer, ${ }^{20}$ whereas PROMs take less time to complete but are more prone to subjective bias (such as depression-associated cognitive distortions). Regardless, there is usually a good correlation between scores on clinician-rated and patient-rated scales, ${ }^{21}$ so either type of scale can be used for MBC. Of course, like with laboratory tests, treatment decisions should not be made solely based on scores from outcome scales. Instead, the scores must be interpreted along with other data, within the patient's individual context.

\section{Treatment Algorithms}

A treatment algorithm is a guideline that facilitates decision-making through a sequenced, stepwise approach for treatment recommendations. ${ }^{22}$ In conjunction with valid outcome scales, an empirically based algorithm for treatment decisions can be employed to deliver more systematic and optimized care. ${ }^{23}$ Many clinical guidelines provide algorithms for clinical decisions. For example, the Canadian Network for Mood and Anxiety Treatments (CANMAT) clinical guideline on pharmacological treatments for $\mathrm{MDD}^{24}$ provides first-line treatment options for MDD and strategies for managing patients who do not respond to the first medication. ${ }^{24}$ The Texas Medication Algorithm Project (TMAP) is another example of an algorithm that was designed to enhance the quality of pharmacotherapeutic intervention for depression by increasing the consistency of treatment among clinicians and promoting mutually agreed-upon decisions between patient and clinician. ${ }^{25}$ In a study exploring the effectiveness of TMAP, patients with MDD in clinics using the algorithm 
Table I Examples of Validated Outcome Scales for Measurement-Based Care of Depression

\begin{tabular}{|c|c|c|}
\hline Outcome & Clinician-Rated & Patient-Rated \\
\hline Symptoms & $\begin{array}{l}\text { - Hamilton Depression Rating Scale (HAM-D) })^{32} \\
\text { - Montgomery-Asberg Depression Rating Scale } \\
\text { (MADRS) }{ }^{74} \\
\text { - Inventory for Depressive Symptomatology (IDS) })^{75}\end{array}$ & $\begin{array}{l}\text { - Patient Health Questionnaire (PHQ-9) } \\
\text { - Quick Inventory for Depressive Symptomatology, Self-Rated (QIDS-SR) })^{30} \\
\text { - Clinically Useful Depression Outcome Scale (CUDOS) } \\
\text { - Patient-Reported Outcomes Measurement Information System (PROMIS) } \\
\text { depression scale }\end{array}$ \\
\hline Functioning & $\begin{array}{l}\text { - Multidimensional Scale of Independent Functioning } \\
\text { (MSIF) } \\
\text { - WHO Disability Assessment Scale (WHO-DAS) } \\
\text { - Social and Occupational Functioning Assessment } \\
\text { Scale (SOFAS) })^{79}\end{array}$ & $\begin{array}{l}\text { - Lam Employment Absence and Productivity Scale (LEAPS) }{ }^{37} \\
\text { - Sheehan Disability Scale (SDS) } \\
\text { - WHO-DAS, self-rated }{ }^{80} \\
\text { - Work Limitations Questionnaire (WLQ) } \\
\text { - Work Productivity and Activity Impairment (WPAI) scale }{ }^{82}\end{array}$ \\
\hline Side Effects & - UKU Side Effect Rating Scale ${ }^{83}$ & - Frequency, Intensity and Burden of Side Effects Rating (FIBSER) ${ }^{31}$ \\
\hline $\begin{array}{l}\text { Quality of } \\
\text { Life }\end{array}$ & - Quality of Life Interview (QOLI) ${ }^{84}$ & $\begin{array}{l}\text { - EuroQoL-5D (EQ-5D-5L) }{ }^{60} \\
\text { - PROMIS Global-1085 } \\
\text { - Quality of Life, Enjoyment and Satisfaction Questionnaire (QLESQ) }\end{array}$ \\
\hline
\end{tabular}

displayed significantly better improvement in depressive symptom and quality of life outcomes compared to patients in matched clinics offering usual care. ${ }^{25}$

Although algorithms and guidelines may be evidencebased, the reality is that research evidence may not be directly applicable to the complexities of real-world clinical practice. Hence, clinicians are reminded that they must still take into account the unique patient context and tailor treatments to the individual patient. $^{24}$

\section{Efficacy and Utility of MBC for Depression}

Many reviews have highlighted the extensive empirical evidence that supports the utility of $\mathrm{MBC}$ in adult patients. ${ }^{10,11,26}$ However, the randomized controlled trial (RCT) evidence for efficacy is sparse, in part because of methodological heterogeneity in patient populations, settings, and outcome measures. ${ }^{27}$ A 2008 meta-analysis of 12 studies found a significant effect of outcome feedback to clinicians on short-term mental health outcomes, but the effect size $(\mathrm{d}=0.10 ; 95 \%$ confidence interval $[\mathrm{CI}], 0.01-$ 0.19) was small. ${ }^{28}$ In contrast, a recent Cochrane systematic review was only able to include 12 RCTs using broad PROMs in adults with common mental disorders seen in multidisciplinary mental health or psychotherapy clinics. ${ }^{29}$ There was no difference in symptom outcomes between PROM feedback and no-feedback conditions but the quality of evidence was rated as low. ${ }^{29}$
Although MBC can be used for any treatment, ${ }^{10}$ it may be particularly useful for pharmacological management of adult depression where the efficacy of $\mathrm{MBC}$ is clearer. RCTs have shown that MBC, compared to usual care, improves both response and remission rates, as well as patient adherence to antidepressants. For example, Guo et al conducted a randomized, 24-week trial in a hospital outpatient clinic with 120 patients with MDD who were starting an antidepressant medication. ${ }^{87}$ The clinicians could choose to treat the patients in an open-label manner with either paroxetine or mirtazapine. The patients were randomized into either $\mathrm{MBC}$ or standard care; those in MBC completed the Quick Inventory of Depressive Symptomatology, Self-Rated (QIDS-SR) ${ }^{30}$ and Frequency, Intensity, and Burden of Side Effects Rating $(\text { FIBSER })^{31}$ questionnaires at each visit, with scores given to their doctors to aid their decision-making for guidelinesconcordant medication dose adjustment. Raters assessing patient outcomes were blinded to the randomized condition. Based on the primary Hamilton Depression Rating Scale $^{32}$ outcomes over the course of 24 weeks, patients in the $\mathrm{MBC}$ condition achieved significantly higher response ( $87 \%$ vs. $63 \%, p=0.002)$ and remission $(74 \%$ vs. $29 \%$, $\mathrm{p}<0.001)$ rates in comparison to the patients in standard care. Rates of study discontinuation did not differ between the two conditions, suggesting that patients did not find completing the questionnaires at each visit to be an undue or intolerable burden. 
Likewise, in a larger study involving over 900 patients, Yeung et al led a 6-month cluster-matched trial in primary care with the assignment of clinics to either MBC or standard care. ${ }^{88}$ Recruited patients were being treated for depression in primary care settings and were starting an antidepressant. In the MBC group, patients completed the Personal Health Questionnaire (PHQ-9) ${ }^{33}$ by telephone once a month and the scores were given to physicians who used them to guide their treatment decisions. After adjustment for demographic and clinical variables, the MBC group demonstrated twice the odds of attaining response (odds ratio [OR] 2.02, 95\% CI 1.36-3.02) and 1.5 times the odds of attaining remission (OR 1.59, 95\% CI 1.07-2.37) compared to the standard care group. Further, the study also explored the patients' adherence to medications, in which they found that MBC group showed greater adherence $(79 \%$ vs. $67 \%, \mathrm{p}<0.01)$ compared to the standard care group. ${ }^{34}$

The clinical utility of MBC for antidepressant treatment of depression can be illustrated in some simple scenarios described in Table 2. In these scenarios, compared to a clinician's global assessment, the use of an outcome scale can identify at-risk situations and change the medication decision. Scenario 1 describes a situation where it may be difficult to detect early symptom change when a patient does not experience mood improvement. A depressive symptom scale such as the PHQ-9 or QIDSSR can detect small changes in each symptom item that leads to a change in the total score. Typically, a change in the total score of $\geq 20 \%$ from baseline is usually greater than measurement error and day-to-day fluctuations in mood state, and thus is indicative of early clinical improvement. ${ }^{35}$ While a clinician may also detect small changes by inquiring about each symptom, these scales can save time and allow the clinician to focus on the most troubling symptoms. For the PHQ-9, a change of 5 points reflects a change of 2 standard deviations and is used to trigger a change in treatment. ${ }^{36}$

In Scenario 2a, the patient has experienced a clinical response both globally and by the QIDS-SR score, typically defined as $\geq 50 \%$ improvement from baseline score. However, the patient has not yet attained the important goal of symptom remission, which is defined individually for each scale (eg, score of 0-4 for PHQ-9; 0-5 for QIDS$\mathrm{SR})$. In this case, MBC helped inform the decision to increase the medication dose. Again, using an outcome scale can more efficiently assess for symptom remission because clinicians do not need to inquire about every symptom. Scenario $2 \mathrm{~b}$ shows the benefit of using a scale to assess medication side effects to optimize treatment adherence. The FIBSER is a simple 3-item assessment of frequency, intensity and burden of medication side effects; clinical decisions are based on the item that assesses the degree that side effects interfere with day-to-day activities. When side effect burden is rated as $0-2$ (none, minimal or mild interference with activities), no action is needed, whereas ratings of 3-4 (moderate to marked interference) suggest that the side effect needs to be addressed (eg, by lowering the dose or using an antidote) and ratings of 5-6 (severe interference or being unable to function) usually requires changing treatment. $^{31}$

Scenario $2 \mathrm{c}$ illustrates how results from a work functioning scale can alter treatment. The patient's symptom scores are now in the remission range, with resulting improvement in social and family/home functioning. However, the Lam Employment Absence and Productivity Scale (LEAPS) ${ }^{37}$ score of 11 indicates that the patient is still having moderate work impairment, in part related to symptoms such as cognitive difficulties that only manifest while at work. Options include raising the dose or adding psychotherapy; in this case, moderate side effect burden and patient preference guide the treatment decision towards the addition of cognitive-behavioural therapy. Finally, Scenario 3 illustrates the benefit of using MBC during maintenance treatment to assess for signs of early relapse or recurrence. In this case, the patient completes the scales regularly at home and returns to the clinic for early intervention when scores are persistently above the remission threshold.

Although MBC is particularly useful for medication treatment and dose adjustments, $\mathrm{MBC}$ is also relevant and useful in psychotherapy. ${ }^{10}$ For example, mood monitoring and tracking is a foundational element of cognitive-behavioural therapy. ${ }^{38}$ Routine outcome monitoring may be particularly beneficial to identify patients who are not responding to treatment in order to consider early alternative action. ${ }^{28,39} \mathrm{MBC}$ is also an important component of organized systems of primary mental health care, such as chronic disease management ${ }^{40}$ and collaborative care. ${ }^{41}$ For these reasons, both clinical guidelines $^{8}$ and recent policy statements ${ }^{42}$ have called for the broad implementation of MBC for depression management. 
Table 2 Scenarios Illustrating the Impact on Medication Decisions Using Measurement-Based Care versus Usual Care

\begin{tabular}{|c|c|c|c|}
\hline & & Usual Care & $\begin{array}{l}\text { Measurement-Based Care (Scores in } \\
\text { Brackets) }\end{array}$ \\
\hline Baseline & $\begin{array}{l}\text { For the past } 5 \text { months, Jordan has been } \\
\text { experiencing clear episodes of depressed } \\
\text { mood with many depressive symptoms. }\end{array}$ & $\begin{array}{l}\text { - After assessment, the psychiatrist } \\
\text { reviews the diagnosis of MDD with } \\
\text { Jordan and prescribes an antide- } \\
\text { pressant medication. }\end{array}$ & $\begin{array}{l}\text { - Jordan completes the scales and reviews } \\
\text { them with the psychiatrist. } \\
\text { - The QIDS-SR (I6) indicates severe depres- } \\
\text { sive symptoms and the SDS (26) indicates } \\
\text { marked functional impairment. } \\
\text { - The psychiatrist reviews the diagnosis of } \\
\text { MDD with Jordan and prescribes an anti- } \\
\text { depressant medication. } \\
\text { - Given the severity of the depression, they } \\
\text { mutually decide to wait on psychotherapy } \\
\text { until the symptoms have begun to improve. } \\
\text { - The psychiatrist notes that the scales can } \\
\text { help to monitor treatment progress. }\end{array}$ \\
\hline $\begin{array}{l}\text { Scenario } \\
\text { I }\end{array}$ & $\begin{array}{l}\text { At a follow-up visit at } 3 \text { weeks, Jordan } \\
\text { returns to the clinic and reports, "I am } \\
\text { still not feeling good, doctor. My mood } \\
\text { hasn't improved." }\end{array}$ & $\begin{array}{l}\text { - Given the lack of improvement, the } \\
\text { psychiatrist decides toincrease the } \\
\text { doseof medication. }\end{array}$ & $\begin{array}{l}\text { - The scales are completed and reviewed } \\
\text { - Thith Jordan. } \\
\text { severe depressive symptoms; although the } \\
\text { mood item is unchanged, there are slight } \\
\text { improvements in the sleep, energy and } \\
\text { concentration items. } \\
\text { - The SDS score (22) still indicates marked } \\
\text { functional impairment. } \\
\text { - The psychiatrist explains that } \geq 20 \% \text { reduc- } \\
\text { tion in QIDS-SR indicates a measurable } \\
\text { improvement in symptoms and the SDS also } \\
\text { shows some early functional improvement. } \\
\text { - They discuss the discrepancy between lack } \\
\text { of mood improvement and early improve- } \\
\text { ment in other depressive symptoms. } \\
\text { - Given this indication of early improvement, } \\
\text { they mutually decide to keep the same dose } \\
\text { of medication to see whether there will be } \\
\text { a subsequent improvement in mood. }\end{array}$ \\
\hline $\begin{array}{l}\text { Scenario } \\
2 a\end{array}$ & $\begin{array}{l}\text { At a follow-up visit at } 8 \text { weeks, Jordan } \\
\text { reports, "Thanks, doctor, I am feeling } \\
\text { much better." }\end{array}$ & $\begin{array}{l}\text { - Given the clear improvement, the } \\
\text { psychiatrist decides to keep the } \\
\text { same dose of medication. }\end{array}$ & $\begin{array}{l}\text { - The scales are completed and reviewed } \\
\text { with Jordan; } \\
\text { - The QIDS-SR (8) indicates mild depressive } \\
\text { symptoms. The FIBSER side effect burden } \\
\text { score (2) indicates mild interference. } \\
\text { - The psychiatrist explains that even though } \\
\text { Jordan has a clinical response ( } \geq 50 \% \\
\text { reduction in QIDS-SR), there are still resi- } \\
\text { dual symptoms on sleep, energy and con- } \\
\text { centration items that might improve with } \\
\text { a higher dose. } \\
\text { - Given that Jordan's side effect burden is } \\
\text { tolerable, they mutually decide to increase } \\
\text { the dose of medication. }\end{array}$ \\
\hline
\end{tabular}

(Continued) 
Table 2 (Continued).

\begin{tabular}{|c|c|c|c|}
\hline & & Usual Care & $\begin{array}{l}\text { Measurement-Based Care (Scores in } \\
\text { Brackets) }\end{array}$ \\
\hline $\begin{array}{l}\text { Scenario } \\
2 b\end{array}$ & $\begin{array}{l}\text { At a follow-up visit at } 8 \text { weeks, Jordan } \\
\text { reports, "I'm feeling better, but l'm having } \\
\text { some pretty bad side effects from the } \\
\text { medication." }\end{array}$ & $\begin{array}{l}\text { - The psychiatrist decides to switch } \\
\text { the antidepressant to another one. }\end{array}$ & $\begin{array}{l}\text { - The scales are completed and reviewed } \\
\text { with Jordan. } \\
\text { - The QIDS-SR (8) indicates mild depressive } \\
\text { symptoms. } \\
\text { - The FIBSER indicates that although the side } \\
\text { effects are markedly severe (4), they have } \\
\text { low frequency (2) and low interference with } \\
\text { activities (I). } \\
\text { - Given a response on the QIDS-SR ( }>50 \% \\
\text { improvement from baseline), the psychia- } \\
\text { trist discusses ways to cope with the side } \\
\text { effects. } \\
\text { - After discussion, they mutually decide to } \\
\text { stay on the same antidepressant. }\end{array}$ \\
\hline $\begin{array}{l}\text { Scenario } \\
2 c\end{array}$ & $\begin{array}{l}\text { At a follow up visit at } 8 \text { weeks, Jordan } \\
\text { reports, "I am feeling well and almost back } \\
\text { to my usual self." }\end{array}$ & $\begin{array}{l}\text { - The psychiatrist decides to maintain } \\
\text { the dose of antidepressant. }\end{array}$ & $\begin{array}{l}\text { - The scales are completed and reviewed } \\
\text { with Jordan. } \\
\text { - The QIDS-SR (4) indicates minimal symp- } \\
\text { toms in the remission range. } \\
\text { - The SDS (I0) indicates moderate functional } \\
\text { impairment with the LEAPS (II) showing } \\
\text { moderate work impairment. The FIBSER (3) } \\
\text { indicates a moderate burden of side effects. } \\
\text { - In discussion, Jordan feels unable to tolerate } \\
\text { an increase in dose and prefers a non- } \\
\text { medication treatment. } \\
\text { - They mutually decide to add CBT, which has } \\
\text { been shown to improve work functioning in } \\
\text { patients taking antidepressants. }{ }^{89}\end{array}$ \\
\hline $\begin{array}{l}\text { Scenario } \\
3\end{array}$ & $\begin{array}{l}\text { At a follow up visit at } 16 \text { weeks, Jordan } \\
\text { reports, "I am now feeling and doing well, } \\
\text { but what happens now?" }\end{array}$ & $\begin{array}{l}\text { - The psychiatrist notes that the anti- } \\
\text { depressant should be continued for } \\
\text { another 6-8 months. }\end{array}$ & $\begin{array}{l}\text { - The scales are completed and reviewed } \\
\text { with Jordan. } \\
\text { - Scores on the QIDS-SR, SDS, LEAPS and } \\
\text { EQ-5D are all in the remission range. } \\
\text { - The psychiatrist notes that the antidepres- } \\
\text { sant should be continued for another 6-8 } \\
\text { months. } \\
\text { - Jordan monitors mood changes by complet- } \\
\text { ing the scales at home every } 2 \text { months. } \\
\text { - Jordan returns to the clinic when the QIDS- } \\
\text { SR (9) indicates mildly severe symptoms for } \\
\text { more than } 2 \text { weeks, suggesting early relapse } \\
\text { of symptoms. }\end{array}$ \\
\hline
\end{tabular}

Abbreviations: MDD, major depressive disorder; QIDS-SR, Quick Inventory of Depressive Symptomatology, Self-Rated; SDS, Sheehan Disability Scale; FIBSER, Frequency, Intensity, Burden of Side Effects Rating; LEAPS, Lam Employment Absence and Productivity Scale; CBT, cognitive-behavioural therapy; EQ-5D, EuroQoL-5D.

\section{Barriers and Facilitators to MBC Implementation}

Despite the evidence and recommendations for $\mathrm{MBC}$, there is still a significant care gap in the implementation and routine use of MBC. ${ }^{43}$ Except within a few health care systems where routine outcome monitoring is an established practice (eg, in the United Kingdom ${ }^{44}$ and the Netherlands ${ }^{45}$ ), only a minority of physicians and mental 
Table 3 An Example of Recommended Patient-Rated Scales for Measurement-Based Care for Depression

\begin{tabular}{|c|c|c|c|c|}
\hline Outcome Type & Scale & Number of Items & Time to Complete (Minutes)* & Cost \\
\hline \multirow[t]{3}{*}{ Symptoms } & PHQ-9 or & 9 & $3-5$ & Free \\
\hline & QIDS-SR; & 16 & $5-7$ & Free \\
\hline & GAD-7 & 7 & 3 & Free \\
\hline \multirow[t]{2}{*}{ Functioning } & SDS; & 3 & 3 & May require fee \\
\hline & LEAPS & 9 & $3-5$ & Free for clinical use \\
\hline Quality of Life & EQ-5D & 5 & 3 & Free for non-commercial organizations \\
\hline Side Effects & FIBSER & 3 & 3 & Free \\
\hline
\end{tabular}

Notes: *Note, these times indicate the time required per individual scale on first-time assessment; however, less time is usually required when several scales are done at once, and when scales are done on repeat assessment.

Abbreviations: PHQ-9, Patient Health Questionnaire; QIDS-SR, Quick Inventory for Depressive Symptomatology, Self-Rated; GAD-7, Generalized Anxiety Disorder scale; SDS, Sheehan Disability Scale; LEAPS, Lam Employment Absence and Productivity Scale; EQ-5D, EuroQoL-5D; FIBSER, Frequency, Intensity, Burden of Side Effects Rating.

health clinicians use $\mathrm{MBC}$ for depression. ${ }^{10}$ Barriers to using MBC can occur at multiple levels including at clinician, organization/system, and patient levels. ${ }^{14,46}$ In a survey of 314 psychiatrists, $61 \%$ indicated that they never or rarely used standardized scales; only $18 \%$ used them frequently or all the time. ${ }^{12}$ However, of the reasons given by psychiatrists for not using a scale, only $28 \%$ responded that they did not believe it would be clinically helpful. ${ }^{12}$ Other reasons included not knowing which scales to use (21\%), taking too much time (34\%), being too disruptive of clinical practice (19\%) and not being trained to use them $(34 \%){ }^{12}$

There are also organizational and system barriers to MBC implementation in clinical practice settings. ${ }^{10}$ Without financial incentives, clinics may find it challenging to incorporate MBC into busy workflow. Training clinicians about $\mathrm{MBC}$ may take additional resources. ${ }^{47}$ Charting and monitoring changes in scales in clinical records may be difficult; those with electronic medical records (EMRs) may need to adapt them to incorporate mental health measurements. There may also be barriers for patients to complete questionnaires, for example, if they do not understand the purpose of the measures or if they are long and burdensome to complete.

Despite these challenges and barriers, there are encouraging facilitators to implement $\mathrm{MBC}$ in clinical practice. ${ }^{14,46}$ Patients report that they enjoy completing the questionnaires and want their clinicians to use the results in their care. ${ }^{48} \mathrm{MBC}$ training can be incorporated into psychiatry and family practice residency curricula and continuing professional development. ${ }^{49-51}$ Comprehensive guides are available for organizations to implement $\mathrm{MBC}$ in diverse clinical settings. ${ }^{52-54}$ In the following sections, we provide some simple solutions and practical recommendations, including the use of new technology tools, as guidance for clinics and individual physicians to incorporate $\mathrm{MBC}$ for depression into their practice.

\section{Practical Use of Scales for MBC of Depression}

Although some research suggests the use of individualized outcome measures may be more acceptable to clinicians, ${ }^{55}$ most guidelines for MBC recommend using standardized outcome scales. We provide an exemplar set of validated, standardized scales for adult patients with depression that we use in our clinic (Table 3). These scales assess important outcomes and address many of the perceived and actual barriers for implementing MBC. The recommended scales are simple, brief, free or low-cost, and available in several languages. We chose PROMs because of efficiency and ease-of-use; the 6 scales take only 10-15 minutes for patients to complete.

For symptoms, we recommend using either the PHQ-9 or the QIDS-SR. Both are based on the nine symptom criteria for MDD in the DSM-5 and thus can be used as a diagnostic aid as well as assessing severity and change over time. The difference between the two is that the PHQ9 includes only single items to assess sleep, appetite/ weight, and psychomotor activity, whereas the QIDS-SR includes separate items to assess the type of insomnia and both psychomotor retardation and agitation, as well as atypical features such as hypersomnia, overeating, and weight gain. Scoring for the QIDS-SR, however, is based only on the nine DSM-5 symptom criteria, so the total scores of the QIDS-SR and PHQ-9 are similar. Of note, the 
PHQ-9 is the only brief symptom scale that includes an assessment of the presence and degree of functional impairment (question 10). Hence, the QIDS-SR is a more comprehensive symptom assessment tool than the PHQ-9, but it requires a separate assessment of impairment. We include the Generalized Anxiety Disorder scale (GAD-7) ${ }^{56}$ as a measure of anxiety because it is so commonly experienced with depression and has implications for treatment. Although some international groups ${ }^{57}$ have recommended the World Health Organization Disability Assessment Schedule (WHO-DAS) ${ }^{58}$ we chose the Sheehan Disability Scale (SDS) ${ }^{59}$ as a global measure of functional impairment because it is widely used in depression studies, particularly in antidepressant clinical trials, and is shorter and quicker to complete. The LEAPS ${ }^{37}$ is included as a more specific measure of work impairment developed for use in patients who continue to work while being treated for depression. Finally, we use the EuroQoL 5D (EQ-5D-5L) ${ }^{60}$ as a brief measure of the quality of life.

Patients can complete the questionnaires in the waiting room before their appointment and score the questionnaires themselves before seeing the psychiatrist, whereupon the scores are reviewed together. The scales are completed at baseline assessment and, because the questions cover the past 1 or 2 weeks, at each subsequent visit which usually occurs every 2-3 weeks during acute treatment. Once patients have remitted, the scales only need to be done every month or two to monitor for relapse. We also have a summary form for the patient record in which the scores for each visit can be easily entered, visually tracked and monitored during treatment; eg, remission criteria are clearly marked as a goal for treatment. All these scales and forms can be downloaded at our website, https://bit.ly/2ZXj6gd.

\section{Technology Tools for MBC}

Of course, many clinicians now have access to EMRs which vary in utility and complexity. Many commercially available EMRs have incorporated measurement for mental health outcomes with dashboards that allow tracking of scores over time with visual graphing of results. An additional value of $\mathrm{MBC}$ facilitated by these platforms is the efficient communication about patients by the care team, including between primary care and psychiatrists. Some EMRs also have the capability to send online PROMs to patients via email, with direct importing of results into the EMR. Academic organizations have also developed simple MBC platforms for electronic data capture of patient-reported outcomes. ${ }^{61}$ More complex (and expensive) health technology incorporating a measurementfeedback system linked to guideline recommendations and decision support is also available and effective for MBC. ${ }^{13,62,63}$ For individuals and organizations that do not have access to EMRs or have difficulty modifying their existing EMR, web-based MBC services may provide a solution. Owl Insights (www.owlinsights.com/) is an example of a commercial service that integrates MBC through a cloudbased platform that includes screening patients for mental health conditions, tracking their progress with PROMs, and providing guidance for evidence-based treatment. With the process largely automated and digitalized, patients can complete questionnaires on their own time and have their data analyzed and sent electronically to the provider for review. ${ }^{64}$ VitalSigns6 is another example of a point-of-care, web-based software program that can be integrated into EMRs to enable $\mathrm{MBC}$ for screening and treatment of depression in primary care settings. $^{65}$

Finally, the emergence of online and mobile apps as potential health technology tools, particularly highlighted during the global COVID-19 pandemic crisis, has made digital mental health increasingly important for mental health care. ${ }^{66}$ The process of putting mood and outcome tracking directly into the hands of patients enables them to become active participants in shared decision-making with their health care providers. For example, we have created MoodFx (pronounced mood effects, www.moodfx.ca), an online mood tracking application optimized for mobile devices. MoodFx is a free, simple, and patient-focused MBC tool that incorporates validated outcome scales (eg, PHQ-9, GAD-7, FIBSER, LEAPS, SDS) with visual results through graphs and charts that patients can print out or show on their mobile device to physicians or other mental health clinicians. Within MoodFx, users can also schedule reminders via text or email to regularly complete questionnaires and subscribe to receive weekly tips on depression self-management (see https://bit.ly/3mG2qTU). Another screening and monitoring app is What's My M3 (https://whats mym3.com/), which can track mood and screen for multiple mental disorders including MDD, bipolar disorder and posttraumatic stress disorder. ${ }^{8,67}$ Depression Monitor is another simple, validated mobile app that uses the PHQ-9 to screen for depression and to illustrate the patient's depressive symptoms to their clinicians. ${ }^{68}$

While these and other digital tools can empower patients, allow clinicians to use scales without major changes to their practice, and support shared decisionmaking within an MBC framework, there are barriers and limitations to using apps for mental health care. 
Online and mobile depression applications still show little uptake by patients, although attention to specific components such as self-tracking, goal setting and educational learning may increase engagement. ${ }^{69}$ Very few mental health apps have been adequately evaluated for effectiveness or harms, ${ }^{70}$ although recent efforts are converging on consensus evaluation frameworks. ${ }^{71,72}$ Security and privacy concerns are paramount among patients, ${ }^{73}$ hence apps should have transparent policies for how data are used, shared and protected. Some patients may have limited access to technology because of financial, language, wireless availability, or digital literacy challenges. Finally, depression-associated cognitive dysfunction may interfere with the patient's use of digital technologies at home.

\section{Conclusion}

There is ample evidence that $\mathrm{MBC}$ is effective in improving treatment outcomes for patients with MDD. MBC benefits patients (to understand and track their symptoms), clinicians (to guide treatment decisions), and organizations (to standardize care and for quality improvement). Even though many clinicians and organizations want to adopt $\mathrm{MBC}$, there are still multiple barriers and challenges for MBC implementation. However, PROMs and new technological tools may address many of the perceived barriers to the use of MBC and allow patients to track their own outcomes and become active participants in shared decision-making. For clinicians and practice settings where technology is not an option, simple methods including the use of "paper-pencil" patient-rated scales and monitoring forms can increase efficiency and streamline workflow for MBC implementation. These recommended solutions can help clinicians to successfully overcome the challenges of adopting MBC and to ensure that patients have access to best practices for depression management and outcomes.

\section{Acknowledgment}

Co-senior authors: Raymond W Lam and Jun Chen.

\section{Funding}

This manuscript was supported by the Enhanced Measurement-Based Care Effectiveness for Depression (EMBED) study, funded by the Canadian Institutes of Health Research (CIHR) and the National Natural Sciences Foundation of China (81761128032) through the Global Alliance on Chronic Disease [CIHR Team Grant: GACD Mental Health, GAC-154985; Agreement \#01709-000]. RHH was supported by a Mach-Gaensslen
Foundation of Canada Award through the UBC Faculty of Medicine Summer Student Research Program.

\section{Disclosure}

Ran Ha Hong reports grants from UBC Faculty of Medicine, during the conduct of the study. Jill K Murphy reports grants from Global Alliance for Chronic Disease/Canadian Institutes of Health Research, during the conduct of the study. Erin E. Michalak has received funding to support patient education initiatives from Otsuka. Trisha Chakrabarty reports grants from Michael Smith Foundation for Health Research and National Research Council Canada, outside the submitted work. Sagar V. Parikh reports grants and personal fees from Takeda, grants from Sage, personal fees from Aifred, Mensante, and Janssen, outside the submitted work. Larry Culpepper reports personal fees from AbbVie Pharmaceuticals, Allergan Pharmaceuticals, Acadia Pharmaceuticals, Eisai, Merck, Takeda and Physicians Postgraduate Press, owns stock in M3 Information, outside the submitted work. Lakshmi N. Yatham reports personal fees from Alkermes, DSP, Merck, Intracellular Therapeutics, Sanofi, Lundbeck, and Sunovion, grants from Allergan, outside the submitted work. Raymond W. Lam reports grants from Canadian Institutes of Health Research, during the conduct of the study; personal fees from Allergan, Canadian Network for Mood and Anxiety Treatments, Canadian Psychiatric Association, Hansoh, Janssen, Lundbeck, Lundbeck Institute, Myriad Neuroscience, Otsuka, and Pfizer, and grants from Asia-Pacific Economic Cooperation, BC Leading Edge Foundation, Healthy Minds Canada, Michael Smith Foundation for Health Research, MITACS, Ontario Brain Institute, St. Jude Medical, University Health Network Foundation, and VGH-UBCH Foundation, outside the submitted work. The authors report no other potential conflicts of interest for this work.

\section{References}

1. Ferrari AJ, Charlson FJ, Norman RE, et al. Burden of depressive disorders by country, sex, age, and year: findings from the global burden of disease study 2010. PLoS Med. 2013;10(11):e1001547. doi:10.1371/journal.pmed.1001547

2. Phillips MR, Zhang J, Shi Q, et al. Prevalence, treatment, and associated disability of mental disorders in four provinces in China during 2001-05: an epidemiological survey. Lancet. 2009;373 (9680):2041-2053. doi:10.1016/S0140-6736(09)60660-7

3. Lam RW, Kennedy SH, Parikh SV, et al. Canadian Network for Mood and Anxiety Treatments (CANMAT) 2016 clinical guidelines for the management of adults with major depressive disorder: introduction and methods. Can J Psychiatry. 2016;61(9):506-509. doi:10.1177/ 0706743716659061 
4. Malhi GS, Bassett D, Boyce P, et al. Royal Australian and New Zealand College of Psychiatrists clinical practice guidelines for mood disorders. Aust N Z J Psychiatry. 2015;49(12):1087-1206. doi: $10.1177 / 0004867415617657$

5. National Collaborating Centre for Mental Health. Depression: The Treatment and Management of Depression in Adults. Updated ed. British Psychological Society and the Royal College of Psychiatrists; 2010.

6. American Psychiatric Association. Practice Guideline for the Treatment of Patients with Major Depressive Disorder. 3rd ed. American Psychiatric Association; 2010.

7. Rush AJ, Trivedi MH, Wisniewski SR, et al. Bupropion-SR, sertraline, or venlafaxine-XR after failure of SSRIs for depression. $N$ Engl J Med. 2006;354(12):1231-1242. doi:10.1056/NEJMoa052963

8. Lam RW, McIntosh D, Wang J, et al. Canadian Network for Mood and Anxiety Treatments (CANMAT) 2016 clinical guidelines for the management of adults with major depressive disorder: section 1 . Disease burden and principles of care. Can J Psychiatry. 2016;61 (9):510-523. doi:10.1177/0706743716659416

9. Trivedi MH, Rush AJ, Wisniewski SR, et al. Evaluation of outcomes with citalopram for depression using measurement-based care in STAR*D: implications for clinical practice. Am J Psychiatry. 2006;163(1):28-40. doi:10.1176/appi.ajp.163.1.28

10. Scott K, Lewis CC. Using measurement-based care to enhance any treatment. Cogn Behav Pract. 2015;22(1):49-59. doi:10.1016/j. cbpra.2014.01.010

11. Fortney JC, Unützer J, Wrenn $\mathrm{G}$, et al. A tipping point for measurement-based care. Psychiatr Serv. 2017;68(2):179-188. doi:10.1176/appi.ps.201500439

12. Zimmerman M, McGlinchey JB. Why don't psychiatrists use scales to measure outcome when treating depressed patients? J Clin Psychiatry. 2008;69(12):1916-1919. doi:10.4088/jcp.v69n1209

13. Black WE, Nagarkatti-Gude DR, Jetmalani A, Keepers G. Harnessing technology to implement measurement-based care. Acad Psychiatry. 2018;42(5):711-716. doi:10.1007/s40596-018-0929-z

14. Lewis CC, Boyd $M$, Puspitasari $A$, et al. Implementing measurement-based care in behavioral health: a review. JAMA Psychiatry. 2019;76(3):324-335. doi:10.1001/jamapsychiatry. 2018.3329

15. Lam RW, Michalak EE, Swinson RP. Assessment Scales in Depression and Anxiety. revised ed. Informa Healthcare; 2006.

16. Lam RW, Parikh SV, Michalak EE, Dewa CS, Kennedy SH. Canadian Network for Mood and Anxiety Treatments (CANMAT) consensus recommendations for functional outcomes in major depressive disorder. Ann Clin Psychiatry. 2015;27(2):142-149.

17. Zimmerman M, McGlinchey JB, Posternak MA, Friedman M, Attiullah N, Boerescu D. How should remission from depression be defined? The depressed patient's perspective. Am J Psychiatry. 2006;163(1):148-150. doi:10.1176/appi.ajp.163.1.148

18. Zimmerman M, McGlinchey JB, Posternak MA, Friedman M, Boerescu D, Attiullah N. Discordance between self-reported symptom severity and psychosocial functioning ratings in depressed outpatients: implications for how remission from depression should be defined. Psychiatry Res. 2006;141(2):185-191. doi:10.1016/j. psychres.2005.05.016

19. McKnight PE, Kashdan TB. The importance of functional impairment to mental health outcomes: a case for reassessing our goals in depression treatment research. Clin Psychol Rev. 2009;29 (3):243-259. doi:10.1016/j.cpr.2009.01.005

20. Uher R, Perlis RH, Placentino A, et al. Self-report and clinician-rated measures of depression severity: can one replace the other? Depress Anxiety. 2012;29(12):1043-1049. doi:10.1002/da.21993

21. Bernstein IH, Rush AJ, Carmody TJ, Woo A, Trivedi MH. Clinical vs. self-report versions of the quick inventory of depressive symptomatology in a public sector sample. J Psychiatr Res. 2007;41(3-4):239-246. doi:10.1016/j.jpsychires.2006.04.001
22. Suehs B, Argo T, Bendele S, Crismon M, Trivedi M, Kurian B. Texas Medication Algorithm Project Procedural Manual: Major Depressive Disorder Algorithms. Texas Department of State Health Services; 2008.

23. Amsterdam JD, Hornig-Rohan M. Treatment algorithms in treatment-resistant depression. Psychiatr Clin North Am. 1996;19 (2):371-386. doi:10.1016/s0193-953x(05)70293-8

24. Kennedy SH, Lam RW, McIntyre RS, et al. Canadian Network for Mood and Anxiety Treatments (CANMAT) 2016 clinical guidelines for the management of adults with major depressive disorder: section 3. Pharmacological treatments. Can J Psychiatry. 2016;61 (9):540-560. doi:10.1177/0706743716659417

25. Trivedi MH, Rush AJ, Crismon ML, et al. Clinical results for patients with major depressive disorder in the Texas medication algorithm project. Arch Gen Psychiatry. 2004;61(7):669-680. doi:10.1001/ archpsyc.61.7.669

26. Aboraya A, Nasrallah HA, Elswick DE, et al. Measurement-based care in psychiatry-past, present, and future. Innov Clin Neurosci. 2018;15(11-12):13-26.

27. Valderas JM, Kotzeva A, Espallargues M, et al. The impact of measuring patient-reported outcomes in clinical practice: a systematic review of the literature. Qual Life Res. 2008;17 (2):179-193. doi:10.1007/s11136-007-9295-0

28. Knaup C, Koesters M, Schoefer D, Becker T, Puschner B. Effect of feedback of treatment outcome in specialist mental healthcare: meta-analysis. Br J Psychiatry. 2009;195(1):15-22. doi:10.1192/bjp. bp. 108.053967

29. Kendrick T, El-Gohary M, Stuart B, et al. Routine use of patient reported outcome measures (PROMs) for improving treatment of common mental health disorders in adults. Cochrane Database Syst Rev. 2016;7:CD011119. doi:10.1002/14651858.CD011119.pub2

30. Rush AJ, Trivedi MH, Ibrahim HM, et al. The 16-item Quick Inventory of Depressive Symptomatology (QIDS), clinician rating (QIDS-C), and self-report (QIDS-SR): a psychometric evaluation in patients with chronic major depression. Biol Psychiatry. 2003;54 (5):573-583. doi:10.1016/s0006-3223(02)01866-8

31. Wisniewski SR, Rush AJ, Balasubramani GK, Trivedi MH, Nierenberg AA. Self-rated global measure of the frequency, intensity, and burden of side effects. J Psychiatr Pract. 2006;12(2):71-79. doi:10.1097/00131746-200603000-00002

32. Hamilton M. A rating scale for depression. J Neurol Neurosurg Psychiatry. 1960;23(1):56-62. doi:10.1136/jnnp.23.1.56

33. Kroenke K, Spitzer RL, Williams JB. The PHQ-9: validity of a brief depression severity measure. J Gen Intern Med. 2001;16(9):606-613. doi:10.1046/j.1525-1497.2001.016009606.x

34. Chang TE, Jing Y, Yeung AS, et al. Depression monitoring and patient behavior in the Clinical Outcomes in MEasurement-Based Treatment (COMET) trial. Psychiatr Serv. 2014;65(8):1058-1061. doi:10.1176/appi.ps.201300326

35. Lam RW. Onset, time course and trajectories of improvement with antidepressants. Eur Neuropsychopharmacol. 2012;22(Suppl 3): S492-S498. doi:10.1016/j.euroneuro.2012.07.005

36. Löwe B, Unützer J, Callahan CM, Perkins AJ, Kroenke K. Monitoring depression treatment outcomes with the patient health questionnaire-9. Med Care. 2004;42(12):1194-1201. doi:10.1097/ 00005650-200412000-00006

37. Lam RW, Michalak EE, Yatham LN. A new clinical rating scale for work absence and productivity: validation in patients with major depressive disorder. BMC Psychiatry. 2009;9:78. doi:10.1186/1471-244X-9-78

38. Parikh SV, Quilty LC, Ravitz P, et al. Canadian Network for Mood and Anxiety Treatments (CANMAT) 2016 clinical guidelines for the management of adults with major depressive disorder: section 2 . Psychological treatments. Can J Psychiatry. 2016;61(9):524-539. doi:10.1177/0706743716659418

39. Lambert MJ. Prevention of Treatment Failure: The Use of Measuring, Monitoring, and Feedback in Clinical Practice. American Psychological Association; 2010. 
40. Kates N, Mach M. Chronic disease management for depression in primary care: a summary of the current literature and implications for practice. Can J Psychiatry. 2007;52(2):77-85. doi:10.1177/ 070674370705200202

41. Wood E, Ohlsen S, Ricketts T. What are the barriers and facilitators to implementing collaborative care for depression? A systematic review. J Affect Disord. 2017;214:26-43. doi:10.1016/j.jad.2017.02.028

42. Fortney J, Sladek R, Unützer J. Fixing Behavioral Health Care in America: A National Call for Measurement-Based Care in the Delivery of Behavioral Health Services. The Kennedy Forum; 2015. Available from: https://thekennedyforum-dot-org.s3.amazonaws.com/ documents/KennedyForum-MeasurementBasedCare_2.pdf. Accessed December 30, 2020.

43. Harding KJK, Rush AJ, Arbuckle M, Trivedi MH, Pincus HA. Measurement-based care in psychiatric practice: a policy framework for implementation. $J$ Clin Psychiatry. 2011;72(8):1136-1143. doi:10.4088/JCP.10r06282whi

44. Macdonald AJ, Fugard AJ. Routine mental health outcome measurement in the UK. Int Rev Psychiatry. 2015;27(4):306-319. doi:10.3109/09540261.2015.1015505

45. Metz MJ, Veerbeek MA, Franx GC, van der Feltz-cornelis CM, de Beurs E, Beekman ATF. A national quality improvement collaborative for the clinical use of outcome measurement in specialised mental healthcare: results from a parallel group design and a nested cluster randomised controlled trial. BJPsych Open. 2017;3 (3):106-112. doi:10.1192/bjpo.bp.116.004366

46. Murphy JK, Liu J, Colquhoun H, et al. Barriers and Facilitators to Implementing Measurement-Based Care for Depression in Shanghai, China: A Situational Analysis. Submitted for publication, 2021.

47. Hatfield DR, Ogles BM. Why some clinicians use outcome measures and others do not. Adm Policy Ment Health. 2007;34(3):283-291. doi:10.1007/s10488-006-0110-y

48. Kendrick T, Stuart B, Leydon GM, et al. Patient-reported outcome measures for monitoring primary care patients with depression: PROMDEP feasibility randomised trial. BMJ Open. 2017;7(3): e015266. doi:10.1136/bmjopen-2016-015266

49. Arbuckle MR, Weinberg M, Kistler SC, et al. A curriculum in measurement-based care: screening and monitoring of depression in a psychiatric resident clinic. Acad Psychiatry. 2013;37(5):317-320. doi:10.1176/appi.ap.12080152

50. Collins C, Mohiuddin S, Kerlek A. Integrating measurement-based care into trainee education. Child Adolesc Psychiatr Clin N Am. 2020;29(4):755-762. doi:10.1016/j.chc.2020.05.002

51. Trivedi MH. How can measurement-based care help improve treatment outcomes for major depressive disorder in primary care? J Clin Psychiatry. 2020;81(2). doi:10.4088/JCP.UT17042BR2C

52. Dollar KM, Kirchner JE, DePhilippis D, et al. Steps for implementing measurement-based care: implementation planning guide development and use in quality improvement. Psychol Serv. 2020;17 (3):247-261. doi:10.1037/ser0000368

53. Connors EH, Douglas S, Jensen-Doss A, et al. What gets measured gets done: how mental health agencies can leverage measurement-based care for better patient care, clinician supports, and organizational goals. Adm Policy Ment Health. 2020. doi:10.1007/s10488-020-01063-w

54. Lewis CC, Puspitasari A, Boyd MR, et al. Implementing measurement based care in community mental health: a description of tailored and standardized methods. BMC Res Notes. 2018;11(1):76. doi:10.1186/s13104-018-3193-0

55. Jensen-Doss A, Smith AM, Becker-Haimes EM, et al. Individualized progress measures are more acceptable to clinicians than standardized measures: results of a national survey. Adm Policy Ment Health. 2018;45(3):392-403. doi:10.1007/s10488-017-0833-y

56. Spitzer RL, Kroenke K, Williams JB, et al. A brief measure for assessing generalized anxiety disorder: the GAD-7. Arch Intern Med. 2006;166(10):1092-1097. doi:10.1001/archinte.166.10.1092
57. Obbarius A, van Maasakkers L, Baer L, Löwe B. Standardization of health outcomes assessment for depression and anxiety: recommendations from the ICHOM Depression and Anxiety Working Group. Qual Life Res. 2017;26(12):3211-3225. doi:10.1007/s11136-017-1659-5

58. World Health Organization. WHO Psychiatric Disability Assessment Schedule (WHO/DAS), with a Guide to Its Use. World Health Organization; 1988.

59. Leon AC, Olfson M, Portera L, et al. Assessing psychiatric impairment in primary care with the sheehan disability scale. Int J Psychiatry Med. 1997;27(2):93-105. doi:10.2190/T8EM-C8YH-373N-1UWD

60. Group TE. EuroQol-a new facility for the measurement of healthrelated quality of life. Health Policy (New York). 1990;16 (3):199-208. doi:10.1016/0168-8510(90)90421-9

61. Zandi PP, Wang YH, Patel PD, et al. Development of the national network of depression centers mood outcomes program: a multisite platform for measurement-based care. Psychiatr Serv. 2020;71 (5):456-464. doi:10.1176/appi.ps.201900481

62. Lyon AR, Lewis CC, Boyd MR, Hendrix E, Liu F. Capabilities and characteristics of digital measurement feedback systems: results from a comprehensive review. Adm Policy Ment Health. 2016;43 (3):441-466. doi:10.1007/s10488-016-0719-4

63. Kurian BT, Trivedi MH, Grannemann BD, Claassen CA, Daly EJ, Sunderajan P. A computerized decision support system for depression in primary care. Prim Care Companion J Clin Psychiatry. 2009;11 (4):140-146. doi:10.4088/PCC.08m00687

64. Hayes E. This Portland company gives mental health providers insights. PortlandBusiness Journal. Accessed June 26, 2020.

65. Trivedi MH, Jha MK, Kahalnik F, et al. VitalSign6: a Primary Care First (PCP-First) model for universal screening and measurement-based care for depression. Pharmaceuticals (Basel). 2019;12(2):71. doi:10.3390/ph12020071

66. Gratzer D, Torous J, Lam RW, et al. Our digital moment: innovations and opportunities in digital mental health care. Can J Psychiatry. 2020:706743720937833. doi:10.1177/0706743720937833

67. Gaynes BN, DeVeaugh-Geiss J, Weir S, et al. Feasibility and diagnostic validity of the M-3 checklist: a brief, self-rated screen for depressive, bipolar, anxiety, and post-traumatic stress disorders in primary care. Ann Fam Med. 2010;8(2):160-169. doi:10.1370/afm.1092

68. BinDhim NF, Shaman AM, Trevena L, Basyouni MH, Pont LG, Alhawassi TM. Depression screening via a smartphone app: cross-country user characteristics and feasibility. $\mathrm{J}$ Am Med Inform Assoc. 2015;22(1):29-34. doi:10.1136/amiajnl-2014-002840

69. Zhang R, Nicholas J, Knapp AA, et al. Clinically meaningful use of mental health apps and its effects on depression: mixed methods study. J Med Internet Res. 2019;21(12):e15644. doi:10.2196/15644

70. Larsen ME, Huckvale K, Nicholas J, et al. Using science to sell apps: evaluation of mental health app store quality claims. NPJ Digit Med. 2019;2:18. doi:10.1038/s41746-019-0093-1

71. Torous JB, Chan SR, Gipson SYT, et al. A hierarchical framework for evaluation and informed decision making regarding smartphone apps for clinical care. Psychiatr Serv. 2018;69(5):498-500. doi:10.1176/appi.ps.201700423

72. Henson P, David G, Albright K, Torous J. Deriving a practical framework for the evaluation of health apps. Lancet Digital Health. 2019;1 (2):E52-E54. doi:10.1016/S2589-7500(19)30013-5

73. Steinfeld B, Franklin A, Mercer B, Fraynt R, Simon G. Progress monitoring in an integrated health care system: tracking behavioral health vital signs. Adm Policy Ment Health. 2016;43(3):369-378. doi:10.1007/s10488-015-0648-7

74. Montgomery SA, Asberg M. A new depression scale designed to be sensitive to change. $B r \quad J \quad$ Psychiatry. 1979;134(4):382-389. doi:10.1192/bjp.134.4.382

75. Rush AJ, Giles DE, Schlesser MA, Fulton CL, Weissenburger J, Burns C. The Inventory for Depressive Symptomatology (IDS): preliminary findings. Psychiatry Res. 1986;18(1):65-87. doi:10.1016/ 0165-1781(86)90060-0 
76. Zimmerman M, Chelminski I, McGlinchey JB, Posternak MA. A clinically useful depression outcome scale. Compr Psychiatry. 2008;49(2):131-140. doi:10.1016/j.comppsych.2007.10.006

77. Kroenke K, Stump TE, Chen CX, et al. Minimally important differences and severity thresholds are estimated for the PROMIS depression scales from three randomized clinical trials. $J$ Affect Disord. 2020;266:100-108. doi:10.1016/j.jad.2020.01.101

78. Jaeger J, Berns SM, Czobor P. The multidimensional scale of independent functioning: a new instrument for measuring functional disability in psychiatric populations. Schizophr Bull. 2003;29 (1):153-168. doi:10.1093/oxfordjournals.schbul.a006987

79. Goldman HH, Skodol AE, Lave TR. Revising axis V for DSM-IV: a review of measures of social functioning. Am J Psychiatry. 1992;149(9):1148-1156. doi:10.1176/ajp.149.9.1148

80. Üstün TB. Measuring Health and Disability: Manual for WHO Disability Assessment Schedule (WHODAS 2.0). World Health Organization; 2009.

81. Lerner D, Amick BC, Rogers WH, Malspeis S, Bungay K, Cynn D. The work limitations questionnaire. Med Care. 2001;39(1):72-85. doi:10.1097/00005650-200101000-00009

82. Reilly MC, Zbrozek AS, Dukes EM. The validity and reproducibility of a work productivity and activity impairment instrument. Pharmacoeconomics. 1993;4(5):353-365. doi:10.2165/00019053199304050-00006

83. Lingjaerde O, Ahlfors UG, Bech P, Dencker SJ, Elgen K. The UKU side effect rating scale. A new comprehensive rating scale for psychotropic drugs and a cross-sectional study of side effects in neuroleptic-treated patients. Acta Psychiatr Scand Suppl. 1987;334:1-100. doi:10.1111/j.1600-0447.1987.tb10566.x
84. Lehman AF. A quality of life interview for the chronically mentally ill. Eval Program Plann. 1988;11(1):51-62. doi:10.1016/01497189(88)90033-X

85. Hays RD, Bjorner JB, Revicki DA, Spritzer KL, Cella D. Development of physical and mental health summary scores from the patient-reported outcomes measurement information system (PROMIS) global items. Qual Life Res. 2009;18(7):873-880. doi:10.1007/s11136-009-9496-9

86. Endicott J, Nee J, Harrison W, Blumenthal R. Quality of life enjoyment and satisfaction questionnaire: a new measure. Psychopharmacol Bull. 1993;29(2):321-326.

87. Guo T, Xiang YT, Xiao L. et al. Measurement-based care versus standard care for major depression: a randomized controlled trial with blind raters. Am J Psychiatry. 2015;172(10):1004-13. doi:10.1176/ appi.ajp.2015.14050652

88. Yeung AS, Jing Y, Brenneman SK. et al. Clinical outcomes in measurement-based treatment (Comet): a trial of depression monitoring and feedback to primary care physicians. Depress Anxiety. 2012;29(10):865-73. doi:10.1002/da.21983

89. Lam RW, Parikh SV, Ramasubbu R, et al. Effects of combined pharmacotherapy and psychotherapy for improving work functioning in major depressive disorder. Br J Psychiatry. 2013;203(5):358-365. doi:10.1192/bjp.bp.112.125237
Neuropsychiatric Disease and Treatment

\section{Publish your work in this journal}

Neuropsychiatric Disease and Treatment is an international, peerreviewed journal of clinical therapeutics and pharmacology focusing on concise rapid reporting of clinical or pre-clinical studies on a range of neuropsychiatric and neurological disorders. This journal is indexed on PubMed Central, the 'PsycINFO' database and CAS, and

\section{Dovepress}

is the official journal of The International Neuropsychiatric Association (INA). The manuscript management system is completely online and includes a very quick and fair peer-review system which is all easy to use. Visit http://www.dovepress.com/testimonials.php to read real quotes from published authors. 